\title{
Evolutionary Game Analysis of Campus Credit Strategy Selection Under Incomplete Information Conditions
}

\author{
Guoshun Ma, Chonghui Ma \\ College of Mathematics and Statistics, Northwest Normal University, Lanzhou, China
}

Email address:

guoshunma@163.com (Guoshun Ma), 18394162168@163.com (Chonghui Ma)

To cite this article:

Guoshun Ma, Chonghui Ma. Evolutionary Game Analysis of Campus Credit Strategy Selection Under Incomplete Information Conditions. Journal of World Economic Research. Vol. 9, No. 1, 2020, pp. 51-57. doi: 10.11648/j.jwer.20200901.18

Received: January 9, 2020; Accepted: January 31, 2020; Published: February 10, 2020

\begin{abstract}
Since the China Banking Regulatory Commission issued relevant policies on standardizing the credit card business of college students in 2009, college students' credit cards have gradually withdrawn from campus loan business. In recent years, with the rapid development of the Internet, "Online campus loan" began to take the college student market as the goal, and quickly entered the university campus through recruiting student cadres to carry out "carpet" promotion activities inside the campus. And seized the current situation of college students' lack of financial knowledge and the psychology of comparative consumption, the business volume expands rapidly. The subsequent malignant events, such as "10g naked loan slip", "huge profits and fund-raising", "some college students jumping off buildings to commit suicide due to their inability to repay the loan", also have a negative impact on the society. In view of the above phenomena, this article combines existing research on existing problems of campus loans, and establishes an evolutionary game model between the campus online loan platform and college student borrowers from the perspective of evolutionary games. The game model has two stable points $(1,1),(0,0)$, namely, the campus loan platform chooses to deceive the borrower, the borrower chooses to break the trust, and the campus loan platform chooses not to deceive the borrower, and the borrower keeps the trust. This paper discusses the influence of the changes of the relevant parameters in the model on the choice of the game strategy, and puts forward some suggestions to establish a two-way scoring mechanism for online lending, increase the financial knowledge reserve and income of college students, and help them establish a correct consumption view to standardize the campus online lending work.
\end{abstract}

Keywords: Campus Online Loan, Evolutionary Game, Replication Dynamic Equation, Evolutionary Stability Strategy

\section{Introduction}

In recent years, with the increasing popularity of the Internet, college student consumer groups are more willing to choose online shopping to meet demand than stores. The wide variety of commodities offered by shopping websites such as jingdong and Tmall continuously stimulates the consumption desire of college students, causing many students to blindly compare with others in the situation of insufficient consumption ability [1]. Due to the limited economic ability of college students, most of their living expenses are given by their parents. The unsatisfied desire to consume impel college students to "open up new roads", and adopt take loans to satisfy their vanity and make irrational consumption. With the rapid development of Internet finance, there has appeared campus loan of the P2P financial service model type [2-8]. The campus loan is intended to provide financial support for college students' entrepreneurial groups. However, some campus network loan platforms have seized the psychology of lacking financial knowledge and comparing consumption of college students. They use the publicity methods such as "low interest, fast payment, only need to provide student ID" to induce student loans to make huge profits. At present, the main profit model of campus loans is to provide installment payment during shopping and collect the installment fee or cash loan to collect interest. College students have few economic sources [9], and often there will be cases of inability to repay their debts, the amount of debt is getting larger and larger, which brings serious psychological burden to the borrower, and ultimately causing irreparable consequences.

According to the data provided by the Internet Loan House, as of December 2018, the cumulative number of P2P online loan platforms in China reached 6610, with a total of 5,536 closed down and problematic online loan platforms, and the 
incidence of closed down and problematic online loan platforms was close down to $84 \%$. At the same time, "Internet Loan House" also conducted statistics on college student online loan data. The western region had the largest proportion of student loans, reaching $73.53 \%$ of the total. The top five borrowing needs were Gansu (11.2), Qinghai (9.95), Guizhou (8.99), Inner Mongolia (6.66), Ningxia (6.37). It can be seen that the campus network loan, as a supplement to the national student loan, provides strong financial support for college students in low-income areas and plays a role of "helping the weak ". However, student loans generally have a high probability of default.

At present, many scholars have studied the campus loan problem. Chunmei Zheng [10] and others believe that there are still many problems in China's campus loans and establish a dynamic game of imperfect information between lending platforms and college students. analyzed the impact of imperfect information on campus lending industry, and put forward relevant Suggestions to regulate the development of campus loan platforms. Mingjun Yao [11] and others analyzed the problems of campus loan at the student level and analyzed the behavior of college students' borrowing; Fei Liu et al [12]. analyzed the $\mathrm{P} 2 \mathrm{P}$ network loan credit risk based on the perspective of evolutionary game, built an evolutionary game model and conducted simulation analysis, and finally put forward countermeasures for credit risk management of network loan. Ruishan Lu et al [13]. conducted a survey on the status quo of college students' integrity education, pointing out that students lack a correct understanding of campus loans and the lack of integrity education in colleges and universities. Under the perspective of evolutionary game, Kairong Su [14] and others established an evolutionary game model of P2P credit model between enterprises under government supervision conditions, obtained the evolutionary and stable strategies of enterprises and government regulatory departments, and pointed out the necessity of government intervention in $\mathrm{P} 2 \mathrm{P}$ online loan market through parameter analysis. Based on the existing research work, based on the campus loan platform and the trustworthiness of college borrowers, this paper establishes an evolutionary game model between campus loan platform and college borrowers to solve the evolutionary stability strategy (ESS). Through the analysis of dynamic phase evolution map and related parameters, it provides effective suggestions for the healthy and stable operation of the campus loan platform.

\section{Strategy Model Construction of Both Sides in Game}

In the model, the game party is the college student and campus loan platform, and it is assumed that both sides of the game are participants of bounded rationality. The game information is asymmetric, and the supervision department has a supervisory role on the campus loan platform [15-16].

It is assumed that college student lenders have two strategies: trustworthiness and non-trustworthiness. College students choose to keep their promise after borrowing money, and they will pay their principal and interest on time when they are due; College students choose to lose their trust after borrowing, and will not pay their principal and interest on time when they expire.

It is assumed that the campus loan platform has two strategies: fraud and non-spoofing. The campus loan platform deceives the borrower with false publicity information, and collects high interest if there is no repayment after the deadline. The campus loan platform did not use propaganda to defraud the borrower, and the overdue payment was charged at the agreed interest rate.

When the campus loan platform does not cheat borrowers, and the college students keep their word, set their respective earnings as $E_{C}, E_{U}$.

When the campus loan platform does not defraud the borrower and the borrower loses the trust, the campus loan platform loses revenue due to the borrower's loss of trust, and will pay more supervision costs. Meanwhile, the campus loan platform will impose a fine on the borrower due to the breach of the borrower's trust. And The borrower will receive additional benefits due to loss of trust and bear the loss of the fine. Therefore, the respective revenues of the two sides of the game are $E_{C}-E_{M}+K, E_{U}+E_{G}-K$ (Where $\mathrm{K}$ is the fine for the overdue unpaid person on the campus loan platform).

When the campus lending platform defrauds the borrower and the borrower is trustworthy, the campus lending platform will receive excess returns. Such as additional interest, handling fees and consulting fees, etc, at this time, the borrower's revenue is reduced due to trustworthiness, recorded as $E_{D}$. At the same time, the trustworthy borrower found that the probability of fraudulent behavior on the campus loan platform was $\lambda(0<\lambda<1)$. The borrower can report to the regulatory authorities when the fraud is discovered by the borrower. The supervisory department imposes a fine on the campus loan platform and set the fine is $\mathrm{R}$. Therefore, the respective revenues of the two sides of the game are $E_{C}+E_{P}-\lambda R, E_{U}-E_{D}$.

When the campus loan platform defrauded the borrower and the borrower loses trust, although the campus loan platform initially collects consulting fees, handling fees and other fees, it has invested more regulatory costs due to the borrower's breach of trust. So set the regulatory costs is $E_{F}$. At the same time, the borrower receives excess returns due to break their promise and set the returns is $E_{e}$. However, because the borrower break promise, the borrower could not find that the campus loan platform was deceiving. Therefore, the supervision department cannot punish the fraud of the campus loan platform, but the campus loan platform can still find the borrower's untrustworthy behavior and impose fines on it. So set their respective revenues $E_{C}-E_{F}+K, E_{U}-E_{D}+E_{e}-K$.

Based on the above assumptions, we can construct a game 
strategy and payment matrix as follows:

Table 1. Game strategy and payment matrix.

\begin{tabular}{lll}
\hline \multirow{2}{*}{ College student lender } & \multicolumn{1}{c}{ campus loan platform } & deceive $(1-x)$ \\
\cline { 2 - 3 } & Not deceive $(x)$ & $E_{U}-E_{D}, E_{C}+E_{P}-\lambda R$ \\
\hline keep promise $(y)$ & $E_{U}, E_{C}$ & $E_{U}-E_{D}+E_{e}-K, E_{C}-E_{F}+K$ \\
Broken promises $(1-y)$ & $E_{U}+E_{G}-K, E_{C}-E_{M}+K$ & \\
\hline
\end{tabular}

From the above payment matrix, according to the replication dynamic equation, a group behavior evolution model of the strategic interaction between the campus loan platform and the college borrower can be established. Assume that in the campus loan platform group, the proportion of platforms that do not deceive college students is $x$, The proportion of platforms that cheat college students is $1-x$;

$$
\begin{aligned}
& U_{x}=(1-y)\left(-E_{M}+K\right)=K-E_{M}+E_{M} y-K y \\
& U_{1-x}=y\left(E_{P}-\lambda R\right)+(1-y)\left(-E_{F}+K\right)=E_{P} y-\lambda R y-E_{F}+K+E_{F} y-K y
\end{aligned}
$$

The average revenue of the campus loan platform is

$$
\bar{U}=x\left(K-E_{M}+E_{M} y-K y\right)+(1-x)\left(E_{P} y-\lambda R y+K-E_{F} y-K y\right)
$$

The replication dynamic equation of the campus loan platform is

$$
\begin{aligned}
& \frac{\dot{x}}{x}=U_{x}-\bar{U} \\
& =K-E_{M}+E_{M} y-K y-\left[x\left(K-E_{M}+E_{M} y-K y\right)+(1-x)\left(E_{P} y-\lambda R y+K-E_{F} y-K y\right)\right]
\end{aligned}
$$

The expected return of college student borrowers is

$$
\begin{aligned}
& V_{y}=(1-x)\left(-E_{D}\right)=E_{D} x-E_{D} \\
& V_{1-y}=x\left(E_{G}-K\right)+(1-x)\left(-E_{D}+E_{e}-K\right)=E_{G} x+E_{D} x-E_{e} x-E_{D}+E_{e}-K
\end{aligned}
$$

The average return of college borrowers is

$$
\bar{V}=y\left(E_{D} x-E_{D}\right)+(1-y)\left(E_{G} x+E_{D} x-E_{e} x-E_{D}+E_{e}-K\right)
$$

The replication dynamic equation of college student lenders is

$$
\begin{aligned}
& \frac{\dot{y}}{y}=V_{y}-\bar{V} \\
& =E_{D} x-E_{D}-\left[y\left(E_{D} x-E_{D}\right)+(1-y)\left(E_{G} x+E_{D} x-E_{e} x-E_{D}+E_{e}-K\right)\right]
\end{aligned}
$$

The replication dynamic equations constructed from the model are

$$
\begin{aligned}
& \dot{x}=x(1-x)\left(-E_{M}+E_{M} y-E_{P} y+\lambda R y+E_{F}-E_{F} y\right) \\
& \dot{y}=y(1-y)\left(-E_{G} x+E_{e} x-E_{e}+K\right)
\end{aligned}
$$

If $E_{G}<K, E_{P}-\lambda R \leq 0$, We set $f(x)=\dot{x}, g(y)=\dot{y}$, and make $f(x)=\dot{x}=0, g(y)=\dot{y}=0$, 
The five equilibrium points of the above evolutionary game system in the plane $\mathrm{Q}$ can be obtained, namely:

$$
O(0,0), A(1,1), B(0,1), C(1,0) D\left(x^{*}, y^{*}\right) \text { among them } x^{*}=\frac{E_{e}-K}{E_{e}-E_{G}}, y^{*}=\frac{E_{M}-E_{F}}{E_{M}-E_{P}+\lambda R-E_{F}}
$$

Based on the assumptions, we have: $0<x^{*}<1$

If $x=x^{*}$, there are $g^{\prime}(x) \equiv 0$, all the points at this time are $\operatorname{ESS}(0 \leq y \leq 1)$.

If $x>x^{*}$, there are $g^{\prime}(0)>0, g^{\prime}(1)<0$, At this time, $y=1$ is the evolution steady state. Therefore, trustworthiness is the optimal strategy for college borrowers (Dynamic phase change is shown in Figure 1).

If $x<x^{*}$, there are $g^{\prime}(0)<0, g^{\prime}(1)>0$, At this time, $y=0$ is the evolution steady state. Therefore, dishonesty is the optimal strategy for college students borrowers (Dynamic phase change is shown in Figure 2).

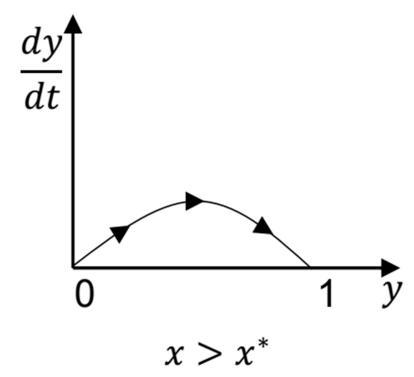

are $\operatorname{ESS}(0 \leq x \leq 1)$.

If $y>y^{*}$, there are $f^{\prime}(0)>0, f^{\prime}(1)<0$, At this time, $x=1$ is the evolution steady state. So not deceiving is the optimal strategy for campus loan (Dynamic phase change is shown in Figure 3).

If $y<y^{*}$, there are $f^{\prime}(0)<0, f^{\prime}(1)>0$, At this time, $x=0$ is the evolution steady state. So deception is the optimal strategy for campus loan (Dynamic phase change is shown in Figure 4).

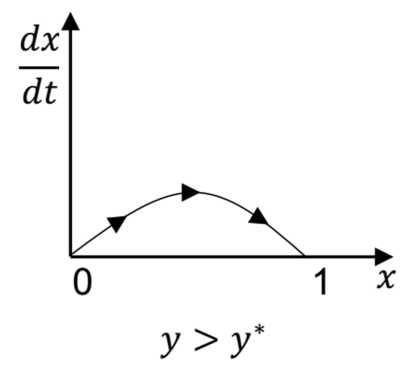

Figure 3. No fraud is the best strategy for campus loans.

Figure 1. Trustworthiness is the best strategy for college student borrowers.
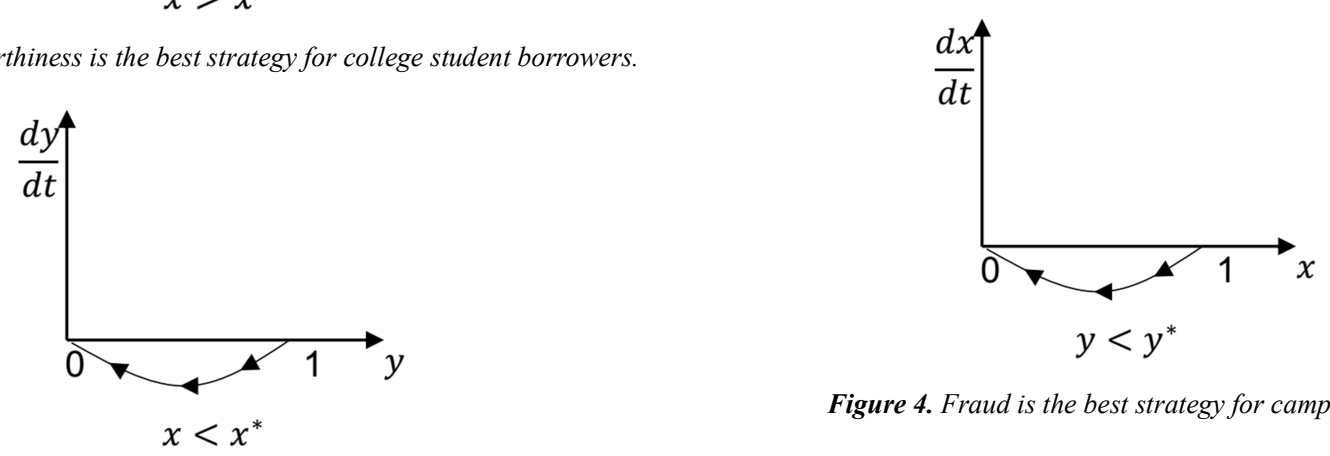

Figure 4. Fraud is the best strategy for campus loans.

Figure 2. Breaking faith is the best strategy for college borrowers.

The Jacobian matrix corresponding to the above replication dynamic equation is

Based on the assumptions, we have: $0<y^{*}<1$

If $y=y^{*}$, there are $f^{\prime}(x) \equiv 0$, all the points at this time

$$
J=\left[\begin{array}{cc}
(1-2 x)\left(E_{M} y-E_{M}-E_{P} y+\lambda R y+E_{F}-E_{F} y\right) & x(1-x)\left(E_{M}-E_{P}+\lambda R-E_{F}\right) \\
y(1-y)\left(-E_{G}+E_{e}\right) & (1-2 y)\left(K-E_{e}+E_{e} x-E_{G} x\right)
\end{array}\right]
$$

The determinant of matrix $J$ is

$$
\begin{aligned}
& \operatorname{det} J=(1-2 x)\left(E_{M} y-E_{M}-E_{P} y+\lambda R y+E_{F}-E_{F} y\right)(1-2 y)\left(K-E_{e}+E_{e} x-E_{G} x\right) \\
& -x(1-x)\left(E_{M}-E_{P}+\lambda R-E_{F}\right) y(1-y)\left(-E_{G}+E_{e}\right)
\end{aligned}
$$

The trace of matrix $J_{\text {is }}$

$$
\operatorname{Tr} J=(1-2 x)\left(E_{M} y-E_{M}-E_{P} y+\lambda R y+E_{F}-E_{F} y\right)+(1-2 y)\left(K-E_{e}+E_{e} x-E_{G} x\right)
$$


Table 2. Stability analysis of equilibrium point.

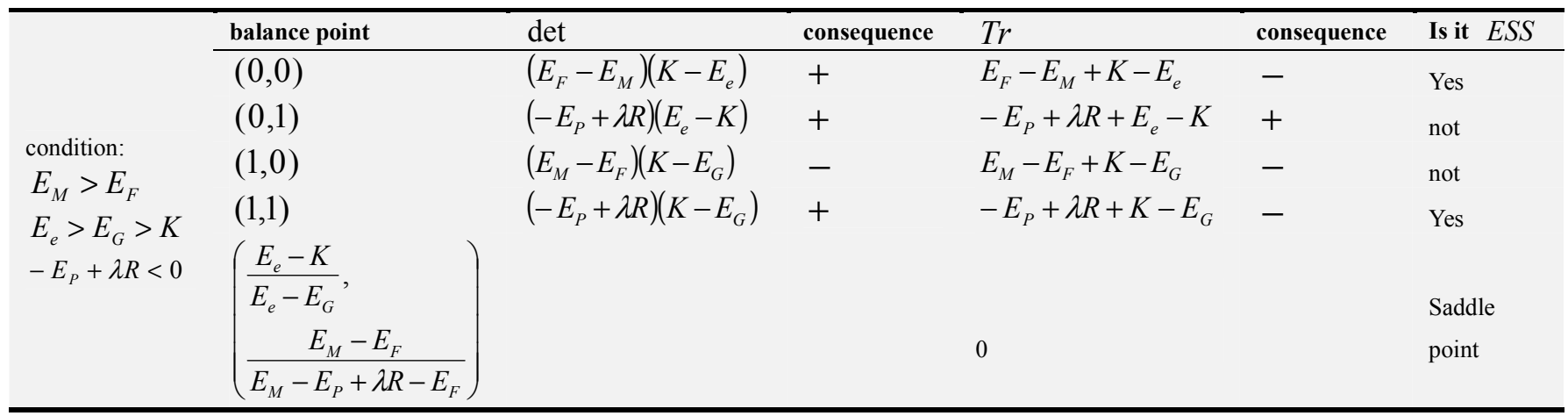

By analyzing the above table, a comprehensive dynamic evolution phase diagram (figure 5) can be obtained.

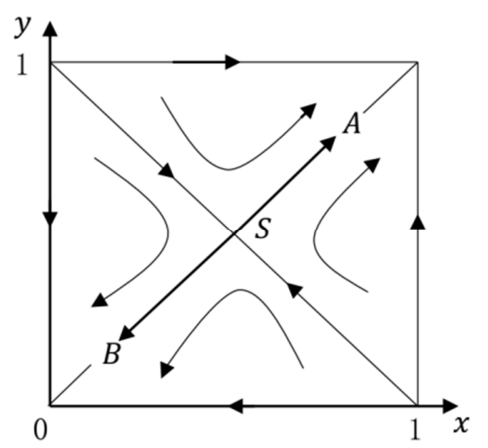

Figure 5. Stages of comprehensive dynamic evolution.

\section{Model Parameter Analysis Discussion}

According to the table and the dynamic evolution phase diagram, it can known that the game model has two stable points, namely $(1,1),(0,0)$. One of the two stable points is the campus loan platform chooses to deceive borrowers, borrowers choose to break promise and the other one is the campus loan platform chooses not to deceive the borrower and the borrower keeps his promise. When the saddle point is in the A area, the system will gradually approach the point $(1,1)$. At this point, the campus loan platform does not defraud the borrower's income more than the fraudulent borrower's income. So not deceiving borrowers is the optimal strategy for the campus loan platform; The borrower gains more when he keeps his word than when he breaks his word. So keeping promise is the optimal strategy for borrowers. The borrower abides by credit and timely repayment, which makes the campus loan platform ensure the liquidity of the fund is good and enhances the overall image of the platform. The campus loan market will develop in a standardized and effective direction. When the saddle point is in the B area, The system will gradually approach the point $(0,0)$. At this point, the campus loan platform deceives the borrower's income more than does not defraud the borrower. So deception is the optimal strategy for the campus loan platform; The income of the borrower who breaks his promise is greater than that of the borrower who keeps his promise. So losing faith is the optimal strategy of the borrower. However, after the campus loan platform defrauds the borrower, it may be reported by the borrower. As a result, the platform's revenue will be reduced, and the platform will impose fines on borrowers who have overdue payments; Borrowers get extra income if they break their promises, Therefore, when the borrower chooses the strategy of breaking faith, the campus network loan platform will take violent collection and other means to recover funds due to the lack of fund recovery, leading to the gradual disorder of the development of the campus loan market. In order to achieve the evolutionary stability expected by the society, the area of region A is gradually increased by adjusting in the game, and the final evolution is near the point $(1,1)$. As can be seen from figure 5 , the above system can approach either the desired ideal state of the society $(1,1)$ or the inefficient bad state $(0,0)$. Which state to approach depends on the initial state of the system, Known by the expression of the saddle point, when the campus lending platform changes the fines for untrustworthy borrowers, the regulatory authorities' changes in the penalties for deceiving college borrowers have changed, the probability that a trustworthy college student borrower reports a campus loan platform will changes, and when the additional fees charged by the campus loan platform other than the loan amount change, the saddle point will move, the area size of the area that causes convergence to both modes will change. According to the rules of these parameter changes, the behavior of the campus loan platform and the college borrowers can be regulated, so that both sides of the game evolve toward the model expected by the society.

When the campus loan platform increases the fines for untrustworthy college borrowers, as the saddle point moves, the area of the area A in Figure 5 increases; When the campus loan platform fines the untrustworthy college borrower, as the saddle point moves, the area of the area B increases. Therefore, when facing the untrustworthy college borrowers, the campus loan platform should increase the fines and encourage the college borrowers to pay the principal and interest on time, so that the system gradually reaches the ideal state expected by the society.

When the supervision department increases the penalty $\mathrm{R}$ of the campus loan platform with deceptive behavior, as the saddle point moves, the area converging to the area $\mathrm{B}$ in Figure 5 decreases, and the area converging to the area $\mathrm{A}$ increases; As R decreases, as the saddle point moves, the area converging to region B in Figure 5 increases, and the area that converges to region A decreases. Therefore, the regulatory 
authorities should increase the punishment for the campus loan platform with deceptive behavior, and promote the campus loan platform to operate in compliance, so that the system gradually reaches the ideal state expected by the society. When the trustworthy borrower increases the reporting ratio $\lambda$ of the campus loan platform with deceptive behavior, as the saddle point moves, the area converges to the area $\mathrm{A}$ in Figure 5 increases, and the area converges to the area $\mathrm{B}$ decreases; When $\lambda$ decreases, as the saddle point moves, the area converges to region A in Figure 5 decreases, and the area converges to region $\mathrm{B}$ increases. This shows that enhancing the awareness of the rights of college borrowers is conducive to the evolution of the system to the state expected by society.

\section{Conclusions and Suggestions}

This paper constructs an evolutionary game model between the campus network loan platform and the university student borrower based on the actual situation. At the same time, it analyzes the game between the campus network loan platform and the university student borrower based on the factors of supervision cost, payment of fine, honesty and overdue, and obtains the optimal strategy for the healthy and stable development of the campus loan. The conclusion shows that the supervision department should increase the intervention to the campus loan market, and the college students' borrowers should strengthen the awareness of self-protection and the popularization of financial knowledge.

Based on the analysis results, the following suggestions are put forward:

(1) Establishment of internet-based credit scoring mechanism for online lending

For the campus loan platform, in order to attract more student loans, it often sets ultra-low loan threshold. This approach makes it impossible for the campus loan platform to grasp all the information of the borrower. Such as whether there is a stable source of financial resources, or whether there has been a fault for credit and so on; For the borrower, there is also information asymmetry, The borrower cannot know whether the campus loan platform collects interest according to the agreement after the payment is overdue, whether it is a usury platform, whether there are problems such as excessive interest collection. Therefore, it is necessary to build an internet-based credit rating system for online loans, and punish students who fail to repay their loans on time. Such as a reduction in the amount of borrowing, fines or the cancellation of the eligibility to borrow again. If the campus loan platform uses propaganda means to blind students to the platform loan, students can also report complaints to the relevant monitoring department. The supervision department punishes the complained campus loan platform until its business qualification is cancelled, so as to maintain the health and safety of campus network loan.

(2) Strengthen the popularization of college students' financial knowledge

The lack of financial knowledge of college students is an important factor that causes the campus loan platform to take advantage of the opportunity to make huge profits. Most students don't know the legal loan process, or even the statutory loan interest rate. Therefore, schools should popularize relevant knowledge, deepen students' understanding of campus loans, and improve their ability to distinguish false propaganda.

(3) Adding work-study positions and entrepreneurship courses

The low economic source of college students is one of the reasons why college students choose campus loans. Therefore, colleges and universities can add student-assisted positions and entrepreneurship-related courses, which not only solves the problem of students' lack of money in students, but also helps students to develop survival skills in the process of entrepreneurship. While increasing students' financial income, it also reduces the probability of students using campus loans.

(4) Guide students to establish a correct view of consumption

Now, the concept of consumption in advance consumption spreads rapidly among college students, college students are increasingly advocating hedonism. In the face of such social situation, schools and families should strengthen the education of social morality and integrity, and help students establish a correct outlook on life, values and consumption.

\section{References}

[1] Jianyou Zhang. Analysis on the current situation of College Students' campus network loan in Guizhou and Research on countermeasures [J]. Economic and trade practice, 2018 (19): 14-15.

[2] Anning Zhang, Xin Gu, Cheng Yang. Analysis on the risk factors of P2P campus loan default [J]. Journal of Finance and accounting, 2018 (06): 82-89.

[3] Jian Yang, Jinxiang Qi, Huiting Wang, Jia Xu. Research on the current situation and risk control of "campus loan" in Colleges and universities $[\mathrm{J}]$. Cooperative economy and technology, 2019 (07): 64-66.

[4] Qiuyu Hong, Dayan Zhu, Xuan Chen. Literature review on the current situation, problems and Countermeasures of "campus loan" [J]. Modern marketing (next ten issues), 2019 (03): 45-47.

[5] Congcong Jiao, Yuqing Jiao, can Li, Xiaoguang Wu, Le Zhang i. The development status and Countermeasures of College Students' Campus loans [J]. China business theory, 2019 (05): 44-46.

[6] Xiong Xiong, Weina Zhang. Research on P2P platform regulatory mechanism based on evolutionary game theory [J]. Economic Research Guide, 2018 (36): 128-129 + 145.

[7] Mingjie Rong, Hualin Liu, Guoxin Li, Kaifan Chen, Jiacheng Liu, Jinyun Liu. Current situation analysis and countermeasure research on campus loan $[\mathrm{J}]$. Modern economic information, 2018 (10): 318.

[8] Zhenglu Han. Game Analysis of P2P network lending behavior [J]. Cooperative economy and technology, 2019 (05): 64-66. 
[9] Shuting Ju, Fanyu Liu, Zhongxia Li. Survey on online loan consumption and financial literacy of college students [J]. Cooperative economy and technology, 2019 (08): 47-49.

[10] Chunmei Zheng, Shanshan Jia. Mechanism design of standardized development of campus loan platform in China from the perspective of game $[\mathrm{J}]$. Foreign trade and economic cooperation, 2016 (09): 120-122 + 132 .

[11] Mingjun Yao, Zhenzhen Zheng, Fengming Wang, shihan Xu, Yingxing Li. Existing problems of campus loan based on the perspective of students $[\mathrm{J}]$. Cooperative economy and technology, 2017 (21): 56-57.

[12] Yan Wang. Why does the campus loan become a "campus disaster"? [N]. democracy and the rule of law times, October 14, 2018 (007).

[13] Fei Liu, Chen Tingting. Evolution mechanism of credit risk of P2P Online Loan -- Analysis Based on evolutionary game [J]. Financial economy, 2018 (12): 124-126.

[14] Lu Ruishan, ang Sal Jiang Abai, Aosheng Wang, Ping Ma. Investigation and Research on the current situation of College Students' Honesty Education Based on the perspective of campus loan $[\mathrm{J}]$. Contemporary education practice and teaching research, 2018 (09): 162-163.

[15] Kairong Su, Yujie Cui. Analysis of P2P online loan mode selection and supervision based on evolutionary game theory [J]. Market modernization, 2015 (15): 74-76.

[16] Wei Zhu. Research on the improvement of legal supervision system of P2P network lending platform [J]. China business theory, 2019 (05): 231-232.
[17] Weibull J W. Evolutionary game theory. Cambridge: MIT Press, 1998, 32-48.

[18] Friedman D. Evolutionary games in economics. Econometric, 1991, (3): 637-666. Fund Project: National Natural Science Foundation of China (No.: 71761031).

\section{Biography}

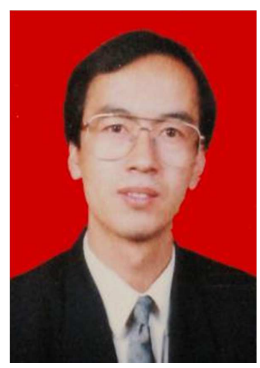

Guoshun Ma (1964-), male, associate professor of Northwest Normal University, postgraduate supervisor, research direction: quantitative economic analysis and game theory application

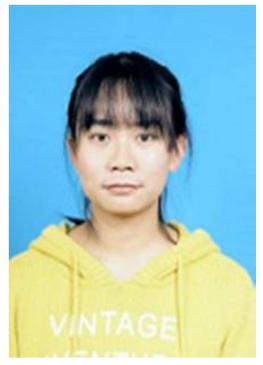

Chonghui Ma (1994-), female, Postgraduate of Northwest Normal University, The research direction is game theory. 